\title{
Mental health in South African adolescents living with HIV: correlates of internalising and externalising symptoms
}

\author{
Mark E. Boyes, Lucie D. Cluver, Franziska Meinck, Marisa Casale and Elizabeth Newnham
}

\begin{abstract}
Although declining in all other age groups, AIDS-related deaths among adolescents are increasing. In the context of HIV, mental health problems are associated with negative health outcomes, including non-adherence to life-saving ART. For effective programming it is essential to identify factors associated with psychological outcomes in this population. Adopting a socioecological perspective, we aimed to identify correlates of internalising and externalising symptoms in a large, representative sample of South African adolescents living with HIV. HIV-positive adolescents $(n=1060)$, who received care in public health facilities in South Africa's Eastern Cape, completed measures of internalising and externalising symptoms. Hypothesised correlates included HIV and health-related factors (physical health, mode of infection, medication side effects, disclosure, stigma), health-service related factors (negative interactions with clinic staff, clinic support group), interpersonal factors (abuse, bullying victimisation, social support), parenting-related factors (orphanhood, positive parenting, parental monitoring, parent communication), as well as individual and demographic-related factors (self-efficacy, age, gender, urban/rural location, poverty). Correlates operating across a variety of contexts were identified. Bullying victimisation, selfefficacy, and positive parenting may be particularly salient intervention targets as they were associated with better outcomes on most or all mental health measures, can be addressed without directly targeting adolescents living with HIV (reducing the chances of accidental exposure and stigma), and are associated with better adolescent mental health in South Africa more generally.
\end{abstract}

Globally, adolescent numbers have more than doubled since 1950, with the majority of adolescents living in low and middle-income countries. Adolescents also rep- resent a growing proportion of people living with HIV and, although declining in all other age groups, AIDS- related deaths among adolescents are increasing (UNI- CEF, 2018). Adolescents are therefore a key population in the fight against HIV. Importantly, in the context of HIV, mental health problems are associated with negative health outcomes, including non-adherence to life-saving ART, morbidity and mortality, as well as risky sexual behaviour, which can transmit drug resistant HIV (Mutumba et al., 2015). Addressing mental health among adolescents living with HIV is therefore an emerging priority (Lowenthal et al., 2014). 
For effective programming it is essential to identify risk and protective factors associated with psychological outcomes. From a socioecological perspective (Bronfenbrenner, 1979), a child is considered the centre of a network of interacting influences operating at different levels (e.g., individual, family, and community). From this viewpoint resources in one area may protect against deficits in another, necessitating that adolescent mental health be conceptualised as multifaceted and influenced by a range of sources. The current paper utilised data collected in a large study of South African adolescents living with HIV (Cluver et al., 2016) to identify correlates of mental health in HIV-positive adolescents. Drawing on limited research on mental health in HIV-positive adolescents, as well as research with adolescents affected by HIV more generally (orphaned adolescents and/or those living with an HIV-positive caregiver), HIV-positive adults, and the broader adolescent mental health literature, we identified a range of potential correlates that were grouped into five categories.

\section{HIV and health-related factors}

Poor physical health (Griffin, Rabkin, Remien, \& Williams, 1998) and ART-related sideeffects (Rong et al., 2017) have been associated with depression and HIV-related stigma is also a salient factor associated with poor mental health in people living with HIV (Rueda et al., 2016). Mode of infection has been linked to adolescent mental health, with higher levels of depression reported in adolescents with behaviourally-acquired HIV (Lewis, Abramowitz, Koenig, Chandwani, \& Orban, 2015). Given the health benefits of HIV-status disclosure, WHO have recommended that school-aged children (typically developing child of 6-12 years) be told their HIV-status (World Health Organization, 2011). Emerging evidence also links HIV-status disclosure with less emotional distress (Menon, Glazebrook, Campain, \& Ngoma, 2007), although some studies report no association (Vreeman et al., 2015).

\section{Health-service related factors}

Little research has focused on health-service interaction and mental health in the context of HIV; however, race and socioeconomic-status related discrimination by health-service providers is associated with depression and posttraumatic stress (Bird, Bogart, \& Delahanty, 2004). African studies report better patient-provider communication and interaction, and more youth-friendly approaches, are associated with better clinic attendance and ART adherence (Ojikutu et al., 2014). Additionally, although there are no data specific to mental health, clinic-linked support groups for HIV-positive adolescents are associated with better ART adherence and health-related outcomes (Wouters, Van Dammeb, Van Loona, van Rensburg, \& Meulemansa, 2009).

\section{Interpersonal factors}

Rates of abuse in South Africa are high and abuse exposure has robust associations with psychological distress (Meinck, Cluver, Boyes, \& Loening-Voysey, 2016; Schneider, Baumrind, \& Kimerling, 2007; Ward, Artz, Leoschut, Kassanjee, \& Burton, 2018). Having experienced physical and sexual abuse and/or family violence is associated with worse mental health 
(anxiety, depression, and posttraumatic stress) among HIV-positive women and youth (Martinez, Hosek, \& Carleton, 2009) as well as among adolescents living with HIV (Woollett, Cluver, Bandeira, \& Brahmbhatt, 2017). Bullying victimisation is strongly linked with adolescent mental health (Arseneault et al., 2008). Being bullied for taking medication has been associated with depression in HIV-positive adolescents in Malawi (Kim et al., 2015) and bullying victimisation mediated associations between familial HIV and depression and anxiety in South African adolescents (Boyes \& Cluver, 2015). Relatedly, social support is associated with less depression in HIV-positive adolescents (Bhana et al., 2016; Gentz, Calonge Romano, Martínez-Arias, \& Ruiz-Casares, 2017).

\section{Parenting-related factors}

A South African study reported better caregiver-child communication was associated with prosocial behaviour, and better caregiver supervision associated with less depression, among perinatally-infected adolescents (Bhana et al., 2016). Additionally, in adolescents affected by familial HIV, positive parenting was associated with better adjustment (Casale et al., 2015) and parental monitoring was negatively associated with anxiety, depression, and conduct problems (Murphy, Marelich, Herbeck, \& Payne, 2009). There is evidence from sub-Saharan Africa that orphaned youth are at elevated risk of mental health problems (Puffer et al., 2012), although contrary findings have been reported (Killian, 2008). No quantitative research has investigated impacts of orphanhood in HIV-positive adolescents; however, qualitative work indicates associations with psychological distress (Woollett, Black, Cluver, \& Brahmbhatt, 2017).

\section{Individual and demographic factors}

Self-efficacy is strongly associated with mental health and has been negatively associated with depression in both adults and adolescents living with HIV (Eller et al., 2014; Seth, Raiji, DiClemente, Wingood, \& Rose, 2009). Demographically, mental health problems increase with age during adolescence, and this association has also been documented in adolescents living with HIV (Kim et al., 2015). Additionally, gender differences in internalising and externalising problems are often observed, with females more likely to develop internalising symptoms and males more likely to display externalising problems. These gender differences have also been reported in HIV-positive adolescents (Kim et al., 2015). Poverty is also associated with worse mental health in in the context of HIV (Cluver et al., 2013; Gentz et al., 2017). Although not specifically linked to mental health in adolescents living with HIV, urban versus rural location can also be a predictor of health outcomes (Casale et al., 2015), possibly due to differences in service access and socio-economic factors.

\section{The current study}

Previous research has identified important correlates that warrant further investigation; however, existing evidence is constrained by four limitations. First, much research is conducted with HIV-positive adults, or adolescents affected by familial HIV, and whether the correlates identified in these groups also apply to HIV-positive adolescents requires investigation. Second, much research is from high-income countries with vastly different 
epidemiological contexts to the generalised epidemic in sub-Saharan Africa. Third, research that is conducted in sub-Saharan Africa often takes place in specialist, well-resourced clinics that may not be representative of broader health systems. Finally, from a socioecological perspective, an adolescent is considered to be at the centre of a network of dynamic influences. Importantly, these influences interact with each other, and resources in one area may protect against deficits in another. Contrasting with this, most previous research focuses on a single or limited number of correlates of adolescent mental health. Additionally, most studies have investigated only a single mental health outcome, usually depression. The current study aimed to address these limitations by investigating whether correlates operating across a variety of contexts were associated with multiple mental health outcomes (both internalising and externalising) in a large and representative sample of South African adolescents living with HIV.

\section{Method}

\section{Participants}

Between March 2014 and September 2015, HIV-positive adolescents ( $n=1060$, aged 10-19 years, $55 \%$ female) were recruited from a health district in the Eastern Cape. The study aimed to recruit all adolescents within the health district eligible to initiate ART. All healthcare facilities providing ART were visited $(n=83)$ and all facilities that reported more than five ART-eligible adolescents were included in the study $(n=39)$. Within facilities, all adolescents who had initiated ART were identified through patient files and computerised records $(n=1176)$ and addresses were recorded for community-tracing. As the study progressed, the Department of Health implemented a healthcare down-referral programme, as a result of which adolescents in the initial 39 facilities were transferred to 53 healthcare facilities. Adolescents were recruited at clinics where they were receiving ART, or traced into their communities. In total, $90.1 \%$ of all study-eligible adolescents were interviewed. The majority of those who did not participate did not provide adolescent and/or caregiver consent (4.1\%) or were untraceable (3.9\%).

\section{Measures}

Mental health: Depression (past two weeks, $\alpha=0.59$ ) was measured with the Child Depression Inventory - Short Form (Kovacs, 1992). Anxiety was measured using an abbreviated version of the Revised Children's Manifest Anxiety Scale (Reynolds \& Richmond, 1978). The scale has been validated in South Africa (Boyes \& Cluver, 2013). The 14 highest loading items $(\alpha=0.79)$ identified previously through factor analysis were administered (Cluver et al., 2013). Posttraumatic stress (past month) was measured with an abbreviated version of the Child PTSD Checklist (Amaya-Jackson, McCarthy, Cherney, \& Newman, 1995). The checklist has been validated in South Africa (Boyes, Cluver, \& Gardner, 2012). The 19 highest loading items $(\alpha=0.89)$ identified in a previous study were administered (Cluver et al., 2013). Conduct problems (preceding six months) were measured with the conduct problems subscale of the well-validated Strengths and Difficulties Questionnaire (Goodman, 1997). Internal consistency in the current sample was low $(\alpha=0.42)$; however, reliability may be underestimated with few items. We therefore checked item-total correlations, all were above 0.30. All mental health 
measures have been used previously with HIV/AIDS-affected adolescents in South Africa (Cluver et al., 2013).

$H I V$ and health-related factors: Physical health (past six months) was assessed with one item (o: Very poor health; 2: Excellent health). Mode of infection (perinatal/behavioural) was determined using an age cut-off and validated with a detailed algorithm in the absence of definitive clinic notes ascribing mode of infection (Sherr, Cluver, Toska, \& He, 2018). Knowledge of HIV-status was determined through healthcare provider report and confirmation by caregiver report during the consent process. Adolescents unaware of their HIV-status $(n=248)$ responded to items on "illness" and "medication" instead of "HIV" and "antiretrovirals". Adolescents aware of their HIV-status reported on any ART-related sideeffects and their age at disclosure, dichotomised into disclosure before and after age 12 (World Health Organization, 2011). HIV-related stigma (enacted, anticipated, and internalised) was measured with the 10-item Adolescents Living with HIV Stigma Scale (Pantelic, Boyes, Cluver, \& Thabeng, 2018).

Health-service related factors: Negative clinic interactions were measured using seven items adapted from the PREPARE Trial (Mathews et al., 2016). Access to a clinic support group was measured using a frequency scale (o: I don't go to one; 4: Weekly). However, $78.8 \%(n=701)$ of adolescents did not attend a support group and this variable was dichotomised (o: Do not attend; 1: Any attendance).

Interpersonal factors: Any past year physical and emotional abuse and life-time contact sexual abuse were measured using items from the UNICEF Measures for National-level Monitoring of Orphans and Other Vulnerable Children (Snider \& Dawes, 2006) and the Juvenile Violence Questionnaire (Hamby, Finkelhor, Ormrod, \& Turner, 2005). Bullying victimisation $(\alpha=0.79)$ was measured using the Social and Health Assessment Peer Victimisation Scale (Ruchkin, Schwab-Stone, \& Vermeiren, 2004). Social support was measured with seven items $(\alpha=0.85)$ from the Medical Outcome Study Social Support Survey (Sherbourne \& Stewart, 1991).

Parenting-related factors: Positive parenting (6 items, $\alpha=0.90)$ and poor parental monitoring/supervision (10 items, $\alpha=0.93$ ) were measured using the short form of the Alabama Parenting Questionnaire (Elgar, Waschbusch, Dadds, \& Sigvaldason, 2007). Parent-child communication was measured using five items $(\alpha=0.45)$ from the ChildParent Communication Apprehension Scale for use with Young Adults (Lucchetti, Powers, \& Love, 2002). Orphanhood was a binary variable (o: Not orphaned; 1 : Orphaned), defined as the loss of one or both parents.

Individual and demographic factors: Demographic information included poverty, age, gender, and urban/rural location. Household poverty was measured using an index of access to the eight highest socially-perceived necessities for South African children and adolescents (Barnes \& Wright, 2012). Self-efficacy was measured using four items $(\alpha=$ o.82) from the General Self-Efficacy Scale (Schwartzer \& Jerusalem, 1995). 


\section{Procedure}

Ethical approvals were obtained from the Universities of Oxford and Cape Town, Eastern Cape Departments of Health and Basic Education, and participating hospitals. Caregivers and adolescents provided written informed consent. Questionnaires were translated into Xhosa, back-translated, and piloted with 25 HIV-positive adolescents. Questionnaires were administered by trained research assistants or via tablet-assisted self-interviewing, depending on literacy level. Participation took approximately $90 \mathrm{~min}$ and no financial incentive for participation was provided. Participants who disclosed abuse, neglect, defaulting from ART, severe hunger, or risk of significant harm were immediately linked to services $(n=66,6.2 \%)$.

\section{Results}

\section{Descriptive statistics and bivariate analyses}

Descriptive statistics for all mental health outcomes, hypothesised correlates, and demographic characteristics (disaggregated by gender) are presented in Table 1, along with the correlations between all hypothesised risk/protective factors and mental health scores. Correlations were small-moderate and in predicted directions (Table 1).

\section{Multivariate analyses}

Multiple linear regression analyses were conducted to determine whether hypothesised correlates accounted for unique variance in mental health scores. For each outcome three models were examined. Model 1 included all correlates. Model 2 retained correlates from first model that were significant at $p<0.10$. Model 3 retained correlates that were significant at $p$ $<0.05$. Table 2 summarises final models for all outcomes (see Supplementary Tables for interim models). To ensure clustering of participants within clinics was not biasing estimates additional multilevel regressions were conducted, with clinic of recruitment included as a random effect. While intraclass correlations (ICC) were significant in unconditional models for depression and posttraumatic stress (Depression: $I C C=0.05, p=$ 0.034; Posttraumatic stress: $I C C=0.11, p=0.016$ ), $I C C$ s were not significant for any of the final models. Model fit of the final original models and multilevel models were compared using the Akaike information criterion $(A I C)$ and the Bayesian information criterion (BIC). All original models $(A I C=579-3531 ; B I C=628-3580)$ demonstrated better fit than multilevel models $(A I C=3437-6333 ; B I C=3447-6343)$. Clustering did not substantially influence results and original analyses are reported.

Depression scores: ART side-effects, negative clinic interactions, internalised stigma, emotional and sexual abuse, bullying victimisation, and age were associated with higher depression scores. Better health, accessing a clinic support group, social support, positive parenting, and self-efficacy were associated with lower depression scores (Table 2). The model accounted for $28 \%$ of the variance in depression scores $\left[R^{2}=0.28, F(12,986)=\right.$ $31.25, p<0.001]$. 
Anxiety scores: ART side-effects, anticipated stigma, internalised stigma, emotional and sexual abuse, bullying victimisation, poor parental monitoring, and poverty were associated with higher anxiety scores. Better health, accessing a clinic support group, positive parenting, and self-efficacy were associated with lower anxiety scores. The model accounted for $36 \%$ of the variance in anxiety scores $\left[R^{2}=0.36, F(12,977)=36.61, p<0.001\right]$.

Table 1. Descriptive statistics (disaggregated by gender).

\begin{tabular}{|c|c|c|c|c|c|c|}
\hline & $\begin{array}{c}\text { Male } \\
(n=476,45 \%)\end{array}$ & $\begin{array}{c}\text { Female } \\
(n=584,55 \%)\end{array}$ & $\begin{array}{l}\text { Depression } \\
\text { score }\end{array}$ & $\begin{array}{c}\text { Anxiety } \\
\text { score }\end{array}$ & $\begin{array}{l}\text { Posttraumatic } \\
\text { stress score }\end{array}$ & $\begin{array}{c}\text { Conduct } \\
\text { problem score }\end{array}$ \\
\hline \multicolumn{7}{|l|}{ Mental health } \\
\hline Depression score $(M, S D)$ & $1.01(1.58)$ & $1.22(1.92)$ & & & & \\
\hline Anxiety score $(M, S D)$ & $1.93(2.34)$ & $2.36(2.82)^{* *}$ & $0.42^{* * *}$ & & & \\
\hline Posttraumatic stress score $(M, S D)$ & $4.27(5.83)$ & $5.78(7.39)^{* * *}$ & $0.31^{* * *}$ & $0.52^{* * *}$ & & \\
\hline Conduct problems score $(M, S D)$ & $1.43(1.41)$ & $1.45(1.47)$ & $0.27^{* * *}$ & $0.29^{* * *}$ & $0.33^{* * *}$ & \\
\hline \multicolumn{7}{|l|}{ HIV and health-related factors } \\
\hline Overall health $(M, S D)$ & $2.40(0.58)$ & $2.32(0.59)^{*}$ & $-0.17^{* * *}$ & $-0.21^{* * *}$ & $-0.23^{* * *}$ & $-0.09^{* *}$ \\
\hline Side-effects $(n, \%)$ & $98(21 \%)$ & $133(25 \%)$ & $0.24^{* * *}$ & $0.25^{* * *}$ & $0.15^{* * *}$ & $0.13^{* * *}$ \\
\hline Mode of infection ( $n, \%$ perinatally infected) & $360(76 \%)$ & $348(60 \%)^{* * *}$ & $0.11^{* *}$ & $0.09^{* *}$ & $0.19^{* * *}$ & 0.04 \\
\hline Disclosed to before age $12(n, \%)$ & $339(71 \%)$ & $351(60 \%)^{* *}$ & $-0.13^{* * *}$ & $-0.09^{* *}$ & $-0.16^{* * *}$ & $-0.08^{* *}$ \\
\hline Enacted stigma $(M, S D)$ & $0.08(0.30)$ & $0.14(.57)^{*}$ & $0.12^{* * *}$ & $0.15^{* * *}$ & $0.18^{* * *}$ & $0.07^{*}$ \\
\hline Anticipated stigma $(M, S D)$ & $0.40(0.81)$ & $0.61(0.99)^{* * *}$ & $0.17^{* * *}$ & $0.25^{* * *}$ & $0.17^{* * *}$ & $0.12^{* * *}$ \\
\hline Internalised stigma $(M, S D)$ & $0.41(0.95)$ & $0.50(1.06)$ & $0.32^{* * *}$ & $0.39^{* * *}$ & $0.34^{* * *}$ & $0.21^{* * *}$ \\
\hline \multicolumn{7}{|l|}{ Health-service related factors } \\
\hline Negative clinic interactions $(M, S D)$ & $4.19(2.06)$ & $3.88(2.37)^{*}$ & $0.14^{* * * *}$ & $0.15^{* * *}$ & 0.04 & 0.04 \\
\hline Clinic support group $(n, \%)$ & $165(35 \%)$ & $194(33 \%)$ & $-0.08^{*}$ & -0.06 & -0.01 & -0.06 \\
\hline \multicolumn{7}{|l|}{ Interpersonal factors } \\
\hline Past year physical abuse $(n, \%)$ & $101(21 \%)$ & $107(18 \%)$ & $0.07^{*}$ & $0.13^{* * *}$ & $0.07^{*}$ & $0.09^{* *}$ \\
\hline Past year emotional abuse $(n, \%)$ & $77(16 \%)$ & $120(21 \%)$ & $0.28^{* * *}$ & $0.37^{* * *}$ & $0.27^{* * *}$ & $0.22^{* * *}$ \\
\hline Lifetime sexual abuse $(n, \%)$ & $7(2 \%)$ & $40(4 \%)^{* * *}$ & $0.23^{* * *}$ & $0.21^{* * *}$ & $0.19^{* * *}$ & $0.14^{* * *}$ \\
\hline Bullying victimisation $(M, S D)$ & $11.24(2.93)$ & $11.45(3.63)$ & $0.23^{* * *}$ & $0.38^{* * *}$ & $0.29^{* * *}$ & $0.20^{* * *}$ \\
\hline Social support $(M, S D)$ & $12.92(2.14)$ & $12.87(2.28)$ & $-0.29^{* * *}$ & $-0.21^{* * *}$ & $-0.15^{* * *}$ & $-0.13^{* * *}$ \\
\hline \multicolumn{7}{|l|}{ Parenting-related factors } \\
\hline Positive parenting $(M, S D)$ & $19.72(4.76)$ & $19.79(5.04)$ & $-0.27^{* * *}$ & $-0.23^{* * *}$ & $-0.30^{* * *}$ & $-0.22^{* * *}$ \\
\hline Poor parental monitoring $(M, S D)$ & $6.64(9.56)$ & $6.23(8.81)$ & $0.10^{* *}$ & $0.15^{* * *}$ & $0.14^{* * *}$ & $0.15^{* * *}$ \\
\hline Parent communication $(M, S D)$ & $16.73(2.75)$ & $16.80(2.85)$ & $-0.19^{* * *}$ & $-0.15^{* * *}$ & $-0.13^{* * *}$ & $-0.11^{* * *}$ \\
\hline Orphaned $(n, \%)$ & $281(59 \%)$ & $339(58 \%)$ & $0.07^{*}$ & 0.02 & 0.04 & 0.03 \\
\hline \multicolumn{7}{|l|}{ Individual and demographic factors } \\
\hline Self-efficacy $(M, S D)$ & $8.33(3.29)$ & $8.60(3.15)$ & $-0.09^{* *}$ & $-0.07^{* *}$ & 0.02 & $-0.14^{* * *}$ \\
\hline Poverty $(M, S D)$ & $1.44(1.70)$ & $1.76(1.87)^{* *}$ & $0.13^{* * *}$ & $0.17^{* * *}$ & $0.12^{* * *}$ & 0.04 \\
\hline Age $(M, S D)$ & $13.31(2.51)$ & $14.26(3.03)^{* * *}$ & $0.19^{* * *}$ & $0.16^{* * *}$ & $0.28^{* * *}$ & $0.13^{* * *}$ \\
\hline Gender female $(n, \%)$ & & & 0.06 & $0.08^{* *}$ & $0.11^{* * *}$ & 0.01 \\
\hline Urban $(n, \%)$ & $377(79 \%)$ & $451(77 \%)$ & -0.01 & -0.02 & $-0.09^{* *}$ & -0.05 \\
\hline
\end{tabular}

Note: ***p<0.001.

${ }^{* *} p<0.01$.

${ }^{*} p<0.05$.

Gender comparisons: ANOVAs and $x^{2}$ tests Correlations: Pearson's $r$ (continuous variables), Point-biserial correlation (when one variable is binary).

Posttraumatic stress scores: Behavioural infection, enacted stigma, internalised stigma, emotional abuse, bullying victimisation, age, and urban location were associated with higher posttraumatic stress scores. Better health and positive parenting were associated with lower posttraumatic stress scores. The model accounted for $32 \%$ of the variance in posttraumatic stress scores $\left[R^{2}=0.32, F(9,1009)=51.45, p<0.001\right]$.

Conduct problem scores: Internalised stigma, emotional abuse, bullying victimisation, age, and urban location were associated with higher conduct problem scores. Positive parenting, self-efficacy, and household poverty were associated with lower conduct problem scores. The model accounted for $17 \%$ of the variance in conduct problem scores $\left[R^{2}=0.17, F(9,999)=22.56, p<0.001\right]$. 


\section{Discussion}

The current study investigated correlates of mental health in a large, representative sample of South African adolescents living with HIV. Consistent with a socioecological perspective (Bronfenbrenner, 1979), factors across a variety of contexts were identified.

In terms of HIV and health-related factors findings were broadly consistent with the adult literature. Better physical health was negatively associated with all measures of internalising symptoms, and although the cross-sectional data preclude conclusions regarding the direction of these associations, findings highlight the importance of continuing to push for early initiation and maintenance of ART among HIV-positive adolescents (Wong, Murray, Phelps, Vermund, \& McCarraher, 2017). However, as in adult studies, ART-related side-effects were associated with depression. Additionally, internalised stigma was associated with worse mental health on all measures. Enacted stigma was associated with more posttraumatic stress and anticipated stigma was associated with higher anxiety scores. If posttraumatic stress symptoms arise as a response to enacted stigma, this pattern is consistent with trauma-specific distress experienced in PTSD and more generalised future-oriented worry in anxiety (Przeworski \& Dunbeck, 2016). Future research should investigate this possibility. Reducing stigma is likely to have positive effects on the mental health of HIV-positive adolescents and although reducing community stigma is difficult (Stangl, Lloyd, Brady, Holland, \& Baral, 2013), it should remain a programming priority.

Table 2. Summary of final mental health regression models.

\begin{tabular}{|c|c|c|c|c|c|c|c|c|}
\hline & \multicolumn{2}{|c|}{ Depression scores } & \multicolumn{2}{|c|}{ Anxiety scores } & \multicolumn{2}{|c|}{ PTSD scores } & \multicolumn{2}{|c|}{ Conduct problem scores } \\
\hline & $B(\mathrm{SE})$ & $\beta$ & $B(\mathrm{SE})$ & $\beta$ & $B(\mathrm{SE})$ & $\beta$ & $B(\mathrm{SE})$ & $\beta$ \\
\hline \multicolumn{9}{|l|}{ HIV and health-related factors } \\
\hline Overall health & $-0.18(0.08)$ & $-0.06^{*}$ & $-0.44(0.12)$ & $-0.10^{* * *}$ & $-1.51(0.31)$ & $-0.13^{* * *}$ & & \\
\hline Side-effects & $0.49(0.12)$ & $0.12^{* * *}$ & $0.51(0.17)$ & $0.08^{* *}$ & & & & \\
\hline $\begin{array}{l}\text { Mode of infection } \\
\text { Disclosed to before age } 12\end{array}$ & & & & & $0.93(0.44)$ & $0.06^{*}$ & & \\
\hline Enacted stigma & & & & & $1.16(0.39)$ & $0.08^{* *}$ & & \\
\hline Anticipated stigma & & & $0.30(0.08)$ & $0.10^{* * *}$ & & & & \\
\hline Internalised stigma & $0.29(0.05)$ & $0.17^{* * *}$ & $0.54(0.07)$ & $0.21^{* * *}$ & $1.36(0.19)$ & $0.20^{* * *}$ & $0.17(0.04)$ & $0.12^{* * *}$ \\
\hline \multicolumn{9}{|l|}{ Health-service related factors } \\
\hline Negative clinic interactions & $0.06(0.02)$ & $0.07^{* *}$ & & & & & & \\
\hline Clinic support group & $-0.32(0.10)$ & $-0.09^{* *}$ & $-0.43(0.14)$ & $-0.08^{* *}$ & & & & \\
\hline \multicolumn{9}{|l|}{ Interpersonal factors } \\
\hline Past year physical abuse & & & & & & & & \\
\hline Past year emotional abuse & $0.56(0.14)$ & $0.12^{* * *}$ & $1.17(0.19)$ & $0.18^{* * *}$ & $1.04(0.51)$ & $0.06^{*}$ & $0.44(0.12)$ & $0.12^{* * *}$ \\
\hline Lifetime sexual abuse & $0.83(0.25)$ & $0.10^{* *}$ & $1.08(0.34)$ & $0.08^{* *}$ & & & & \\
\hline Bullying victimisation & $0.04(0.02)$ & $0.07^{*}$ & $0.15(0.02)$ & $0.20^{* * *}$ & $0.33(0.06)$ & $0.16^{* * *}$ & $0.05(0.01)$ & $0.12^{* * *}$ \\
\hline Social support & $-0.11(0.02)$ & $-0.13^{* * *}$ & & & & & & \\
\hline \multicolumn{9}{|l|}{ Parenting-related factors } \\
\hline $\begin{array}{l}\text { Positive parenting } \\
\text { Poor parental monitoring } \\
\text { Parent communication } \\
\text { Orphaned }\end{array}$ & $-0.04(0.01)$ & $-0.11^{* * *}$ & $\begin{array}{c}-0.05(0.01) \\
0.02(.01)\end{array}$ & $\begin{array}{l}-0.09^{* *} \\
0.06^{*}\end{array}$ & $-0.28(0.04)$ & $-0.21^{* * *}$ & $\begin{array}{c}-.04(0.01) \\
0.02(0.01)\end{array}$ & $\begin{array}{l}-0.14^{* * *} \\
0.11^{* *}\end{array}$ \\
\hline \multicolumn{9}{|l|}{ Individual/demographic factors } \\
\hline $\begin{array}{l}\text { Self-efficacy } \\
\text { Poverty }\end{array}$ & $-0.04(0.02)$ & $-0.07^{*}$ & $\begin{array}{r}-0.06(0.02) \\
0.10(0.04)\end{array}$ & $\begin{array}{l}-0.07^{* *} \\
0.07^{* *}\end{array}$ & & & $\begin{array}{l}-0.08(0.01) \\
-0.05(0.02)\end{array}$ & $\begin{array}{l}-0.18^{* * *} \\
-0.06^{*}\end{array}$ \\
\hline $\begin{array}{l}\text { Age } \\
\text { Female }\end{array}$ & $0.07(0.02)$ & $0.11^{* * *}$ & & & $0.43(0.07)$ & $0.18^{* * *}$ & $0.07(0.02)$ & $0.13^{* * *}$ \\
\hline $\begin{array}{l}\text { Rural/Urban } \\
R^{2}\end{array}$ & & $0.28^{* * *}$ & & $0.36^{* * * *}$ & $-1.91(0.43)$ & $\begin{array}{l}-0.12^{* * *} \\
0.32^{* * *}\end{array}$ & $-0.30(0.10)$ & $\begin{array}{l}-0.08^{* *} \\
0.17^{* * *}\end{array}$ \\
\hline
\end{tabular}


From a health-service perspective, consistent with the adult literature negative clinic interactions were associated with higher depression scores. In contrast, access to clinic support groups appeared to be protective against symptoms of both anxiety and depression. Given clinic support groups may be associated with better ART adherence (Ojikutu et al., 2014; Wouters et al., 2009) and that only a fifth of adolescents in the study reported attending a support group, developing and promoting attendance at clinic support groups could be an important programming target. Alongside this, making clinics more youth friendly (e.g., youth-friendly waiting areas, evening clinic hours, as well as training and better supporting providers regarding adolescent health care) may also help retain adolescents in care (Reif et al., 2016) and improve mental health outcomes. Finally, empathy training for health-service providers may also promote more trusting provider-patient relationships ( $\mathrm{Lin}, \mathrm{Li}, \mathrm{Wan}, \mathrm{Wu}, \&$ Yan, 2012).

Consistent with the broader adolescent mental health literature, as well as research with adolescentsaffectedbyHIV/ AIDS more generally, interpersonal factors appear important correlates of mental health in HIV-positive adolescents. Emotional abuse and bullying victimisation were associated with worse outcomes on all mental health measures. Sexual abuse was associated with higher anxiety and depression scores, while social support appeared protective in relation to depressive symptoms. In terms of parenting-related factors, positive parenting was associated with better mental health across all measures and poor parental monitoring was associated with more anxiety and conduct problems. At the individual level, consistent with both adult and adolescent research in the US, self-efficacy was negatively associated with depression, anxiety, and conduct problems. Predicted age and gender-related associations were also observed.

Bullying victimisation, self-efficacy, and parenting may be particularly salient intervention targets in the context of HIV. They were associated with most or all mental health measures, can be addressed without directly targeting HIV-positive youth (reducing chances of accidental exposure and stigma), and are associated with adolescent mental health more broadly. Anti-bullying interventions in the developed world are effective in reducing bullying, with greatest success when a whole-school approach is implemented (Vreeman \& Carroll, 2007). In Uganda, an intervention aiming to foster change of operational culture within schools has been demonstrated to reduce violence towards students from both staff and peers (Devries et al., 2017). Additionally, school-based resilience programmes have been shown to improve self-efficacy in low and middle-income contexts (Barry, Clarke, Jenkins, \& Patel, 2013). The development, implementation, and evaluation of school-based anti-bullying and resilience-promoting programmes should be a focus of future research. Finally, parenting interventions in sub-Saharan Africa appear to improve child mental health (Betancourt et al., 2017) and reduce abuse (Cluver et al., 2018), an important risk factor across all mental health measures in the current study. Given parenting was also directly associated with internalising and externalising symptoms in the current study, further implementation and evaluation of parenting programmes is warranted. 
The study is not without limitations. Cross-sectional data preclude conclusions regarding temporal associations or causality and longitudinal research is needed. Additionally, the reliability of the depression, conduct problems, and parent communication measure were below accepted thresholds and local clinical cut-offs are not available for the mental health scales. This highlights potential difficulties in applying western-based mental health measures to cultures for which they were not developed. Additionally, mental health problems are often comorbid and future research should attempt to replicate the current findings using techniques in which associations between risk/protective factors and multiple mental health outcomes can be modelled simultaneously. Geographically, the study was limited to one country and findings may not be representative of other low and middle-income contexts. Finally, while there is an existing framework of developmental psychopathology in the context of HIV which has expanded on socioecological theory, this framework is specifically focused on psycho-social needs of children orphaned by HIV (Li et al., 2008). Given the exploratory nature of the current analyses, socioecological theory was chosen as a more general organisational heuristic onto which potential risk and protective factors identified in the literature could be mapped. However, as the study was exploratory in nature, findings require replication in independent samples. Future research refining these findings, and developing a developmental psychopathology framework specific to the experiences of adolescents who are HIV+ would be beneficial.

\section{Conclusions}

Bearing the above limitations in mind, this study addresses constraints of the existing evidence-base by identifying correlates of both internalising and externalising symptoms in HIV-positive adolescents operating across a variety of contexts. Bullying victimisation, selfefficacy, and positive parenting may be particularly salient factors to consider from a programming perspective as they can be addressed without directly targeting HIV-positive youth (reducing chances of accidental exposure and stigma) and are also associated with adolescent mental health more broadly. 


\section{Acknowledgements}

The authors wish to thank all the adolescents who participated in the research, as well as the research assistants who worked tirelessly to gather the data.

\section{Disclosure statement}

No potential conflict of interest was reported by the authors.

\section{Funding}

The study was supported by the Nuffield Foundation under [CPF/41513], Janssen Pharmaceutica N.V., part of the Janssen Pharmaceutical Companies of Johnson \& Johnson, Evidence for HIV Prevention in Southern Africa (EHPSA), a UKAID programme managed by Mott MacDonald [MM/EHPSA/UCT/05150014], the International AIDS Society through CIPHER [155-Hod], the Regional Inter-Agency Task Team for Children Affected by AIDS Eastern and Southern Africa (RIATT-ESA), UNFPA South Africa, UNICEF-ESARO, and the University of Oxford's Clarendon-Green Templeton College Scholarship. Additional support for LC was provided by the European Research Council (ERC) under the European Union's Seventh Framework Programme [FP7/2007-2013/ERC grant agreement no 313421]. Additional support for MB was provided by a New Independent Researcher Infrastructure Award from the Department of Health (Government of Western Australia). EN was supported by a Curtin University Research Fellowship. FM was funded by the Economic and Social Research Council [ES/No17447/1]. Further support for the project is received from the John Fell Fund [161/o33 \& 103/ 757], the Philip Leverhulme Trust [PLP-2014095], and the University of Oxford's ESRC Impact Acceleration Account (IAA) [IAA-MT13003, 1602-KEA-189, 1311- KEA-004 \& 1069-GCRF-227]. 


\section{References}

Amaya-Jackson, L., McCarthy, G., Cherney, M. S., \& Newman, E. (1995). Child PTSD checklist (C). Durham, NC: Duke University Medical Center.

Arseneault, L., Milne, B. J., Taylor, A., Adams, F., Delgado, K., Caspi, A., \& Moffitt, T. E. (2008). Being bullied as an environmentally mediated contributing factor to children's internalizing problems: A study of twins discordant for victimization. Archives of Pediatric and Adolescent Medicine, 162, 145-150. doi:10.1001/archpediatrics

Barnes, H., \& Wright, G. (2012). Defining child poverty in South Africa using the socially percieved necessities approach. In A. Minujin \& S. Nandy (Eds.), Global child poverty and well-being: Measurement, concepts, policy and action (pp. 135-154). Bristol: The Policy Press.

Barry, M., Clarke, A., Jenkins, R., \& Patel, V. (2013). A systematic review of the effectiveness of mental health promotion interventions for young people in low and middle income countries. BMC Public Health, 13, 835.

Betancourt, T., Ng, L., Kirk, C., Brennan, R., Beardslee, W., Stulac, S., ... Sezibera, V. (2017). Family-based promotion of mental health in children affected by HIV: A pilot randomized controlled trial. Journal of Child Psychology and Psychiatry, 58, 922930.

Bhana, A., Mellins, C., Small, L., Nestadt, D., Leu, C., Petersen, I., ... McKay, M. (2016). Resilience in perinatal HIV+ adolescents in South Africa. AIDS Care, 28, 49-59.

Bird, S., Bogart, L., \& Delahanty, D. (2004). Health-related correlates of perceived discrimination in HIV care. AIDS Patient Care and STDs, 18, 19-26.

Boyes, M. E., \& Cluver, L. (2013). Performance of the revised children's manifest anxiety scale in a sample of children and adolescents from poor urban communities in Cape Town. European Journal of Psycholgical Assessment, 29, 113-120.

Boyes, M. E., \& Cluver, L. (2015). Relationships between familial HIV/AIDS and symptoms of anxiety and depression: The mediating effect of bullying victimization in a prospective sample of South African children and addolescents. Journal of Youth and Adolescence, 44, 847-859.

Boyes, M. E., Cluver, L., \& Gardner, F. (2012). Psychometric properties of the child PTSD checklist in a community sample of South African children and adolescents. PLOS ONE, 7, e46905.

Bronfenbrenner, U. (1979). The ecology of human development: Experiments by nature and design. Cambridge: Harvard University Press.

Casale, M., Cluver, L., Crankshaw, T., Kuo, C., Lachman, J., \& Wild, L. (2015). Direct and indirect effects of caregiver social support on adolescent psychological outcomes in two South African AIDS-affected communities. American Journal of Community Psychology, 55, 336-346.

Cluver, L., Meinck, F., Steinert, J., Shenderovich, Y., Doubt, J., Herro Romero, R. ... Gardner, F. (2018). Parenting for life-long health: A pragmatic cluster randomised controlled trial of a non-commercialised parenting programme for adolescents and their families in South Africa. BMJ Global Health, 3(1), eooo539.

Cluver, L., Orkin, M., Boyes, M. E., Sherr, L., Makasi, D., \& Nikelo, J. (2013). Pathways from parental AIDS to child psychological, educational, and sexual risk: Developing 
an empirically-based interactive theoretical model. Social Science and Medicine, 87, 185-193.

Cluver, L., Toska, E., Orkin, M., Meinck, F., Hodes, R., Yakubovich, A., \& Sherr, L. (2016). Achieving equity in HIV-treatment outcomes: Can social protection improve adolescent ARTadherence in South Africa? AIDS Care, 28 (Suppl. 2), 73-82.

Devries, K., Knight, L., Allen, E., Parkes, J., Kyegombe, N., \& Naker, D. (2017). Does the good schools toolkit reduce physical, sexual and emotional violence, and injuries, in girls and boys equally? A cluster-randomised controlled trial. Prevention Science, $18,839-853$.

Elgar, F., Waschbusch, D., Dadds, M., \& Sigvaldason, N. (2007). Development and validation of a short form of the Alabama parenting questionnaire. Journal of Child and Family Studies, 16, 243-259.

Eller, L., Rivero-Mendez, M., Voss, J., Chen, W., Chaiphibalsarisdi, P., Iipinge, S., ... Brion, J. (2014). Depressive symptoms, self-esteem, HIV symptom management self-efficacy and self-compassion in people living with HIV.AIDS Care, 26, 795-803.

Gentz, S., Calonge Romano, I., Martínez-Arias, R., \& Ruiz-Casares, M. (2017). Predictors of mental health problems in adolescents living with HIV in Namibia. Child and Adolescent Mental Health, 22, 179-185.

Goodman, R. (1997). The strengths and difficulties questionnaire: A research note. Journal of Child Psychology and Psychiatry, 38, 581-586.

Griffin, K., Rabkin, J., Remien, R., \& Williams, J. (1998). Disease severity, physical limitations and depression in HIV-infected men. Journal of Psychosomatic Research, 44, 219-227.

Hamby, S., Finkelhor, D., Ormrod, R., \& Turner, H. (2005). The juvenile victimization questionnaire (JVQ): administration and scoring manual. Durham: Crimes Against Children Research Center.

Killian, B. (2008). Psychological distress in orphan, vulnerable children and non-vulnerable children in high prevalence HIV/AIDS communities. Journal of Psychology in Africa, 18, 421-429.

Kim, M., Mazenga, A., Yu, X., Devandra, A., Nguyen, C., Ahmed, S. ... Sharp, C. (2015). Factors associated with depression among adolescents living with HIV in Malawi. BMC Psychiatry, 15, 264.

Kovacs, M. (1992). Children's depression inventory. Niagra Falls, NY: Multi-health Systems. Lewis, J., Abramowitz, S., Koenig, L., Chandwani, S., \& Orban, L. (2015). Negative life events and depression in adolescents with HIV: A stress and coping analysis. AIDS Care, $27,1265-1274$.

Li, X., Naar-King, S., Barnett, D., Stanton, B., Fang, X., \& Thurston, C. (2008). A developmental psychopathology framework of the psychosocial needs of children orphaned by HIV. Journal of the Association of Nurses in AIDS Care, 19, 147-157.

Lin, C., Li, L., Wan, D., Wu, Z., \& Yan, Z. (2012). Empathy and avoidance in treating patients living with HIV/AIDS (PLWHA) among service providers in China. AIDS Care, 24, 1341-1348.

Lowenthal, E., Bakeera-Kitaka, S., Marukuira, T., Chapman, J., Goldrath, K., \& Ferrand, R. (2014). Perinatally acquired HIV infection in adolescents from sub-Saharan Africa: A review of emerging challenges. The Lancet Infectious Diseases, 14, 627-639. 
Lucchetti, A., Powers, W., \& Love, D. (2002). The empirical development of the child-parent communication apprehension scale for Use With young adults. Journal of Family Communication, 2, 109-131.

Martinez, J., Hosek, S., \& Carleton, R. (2009). Screening and assessing violence and mental health disorders in a cohort of inner city HIV-positive youth between 1998-2006. AIDS Patient Care and STDs, 23, 469-475.

Mathews, C., Eggers, S., Townsend, L., Aaro, L., de Vries, P., Mason-Jones, A., ... De Vries, H. (2016). Effects of PREPARE, a multi-component, school-based HIV and intimate partner violence (IPV) prevention programme on adolescent sexual risk behaviour and IPV: Cluster randomised controlled trial. AIDS and Behavior, 2O, 1821-1840.

Meinck, F., Cluver, L., Boyes, M. E., \& Loening-Voysey, H. (2016). Physical, emotional and sexual adolescent abuse victimisation in South Africa: Prevalence, incidence, perpetrators and locations. Journal of Epidemiology and Community Health, 70, 910916.

Menon, A., Glazebrook, C., Campain, N., \& Ngoma, M. (2007). Mental health and disclosure of HIV status in Zambian adolescents with HIV infection: Implications for peersupport programs. JAIDS Journal of Acquired Immune Deficiency Syndromes, 46, 349-354.

Murphy, D., Marelich, W., Herbeck, D., \& Payne, D. (2009). Family routines and parental monitoring as protective factors among early and middle adolescents affected by maternal HIV/AIDS. Child Development, 8o, 1676-1691.

Mutumba, M., Resnicow, K., Bauermeister, J., Harper, G., Musiime, V., Snow, R., \& Lepkowski, J. (2015). Development of a psychosocial distress measure for Ugandan adolescents living with HIV. AIDS and Behavior, 19, 380-392.

Ojikutu, B., Higgins-Biddle, M., Greeson, D., Phelps, B., Amzel, A., Okechukwu, E., ... Hirschhorn, L. (2014). The association between quality of HIV care, loss to follow-up and mortality in pediatric and adolescent patients receiving antiretroviral therapy in Nigeria. PLOS ONE, 9, e100039.

Pantelic, M., Boyes, M. E., Cluver, L. D., \& Thabeng, M. (2018). 'They say HIV is a punishment from God or from ancestors': Cross-cultural adaptation and psychometric assessment of an HIV stigma scale for South African adolescents living with HIV (ALHIV-SS). Child Indicators Research, 11, 207-223.

Przeworski, A., \& Dunbeck, K. (2016). Generalized anxiety disorder: How it compares to PTSD. In C. Martin, V. Preedy \& V. Patel (Eds.), Comprehensive guide to post-traumatic stress disorders (pp. 193-204). Cham: Springer.

Puffer, E., Drabkin, A., Stashko, A., Broverman, S., Ogwang-Odhiambo, R., \& Sikkema, K. (2012). Orphan status, HIV risk behavior, and mental health among adolescents in rural Kenya. Journal of Pediatric Psychology, 37, 868-878.

Reif, L., Bertrand, R., Benedict, C., Lamb, M., Rouzier, V., Verdier, R. ... McNairy, M. (2016). Impact of a youth-friendly HIV clinic: 10 years of adolescent outcomes in Port-au-Prince, Haiti. Journal of the International AIDS Society, 19(1), 20859.

Reynolds, C., \& Richmond, B. (1978). What i think and feel: A revised measure of children's manifest anxiety. Journal of Abnormal Child Psychology, 6, 271-280. 
Rong, H., Nianhua, X., Jun, X., Lianguo, R., Si, W., Sheng, W., ... Xia, W. (2017). Prevalence of and risk factors for depressive symptoms among people living with HIV/ AIDS receiving antiretroviral treatment in Wuhan, China: A short report. AIDS Care, 29, $1524-1528$.

Ruchkin, V., Schwab-Stone, M., \& Vermeiren, R. (2004). Social and health assessment (SAHA) psychometric development summary. New Haven: Yale University.

Rueda, S., Mitra, S., Chen, S., Gogolishvili, D., Globerman, J., Chambers, L., ... Rourke, S. (2016). Examining the associations between HIV-related stigma and health outcomes in people living with HIV/AIDS: A series of meta-analyses. BMJ Open, 6, e011453.

Schneider, R., Baumrind, N., \& Kimerling, R. (2007). Exposure to child abuse and risk for mental health problems in women. Violence and Victims, 22, 620-631.

Schwartzer, R., \& Jerusalem, M. (1995). Generalized self-efficacy scale. In J. Weinman, S. Wright, \& M. Johnston (Eds.), Measures in health psychology: A user's portfolio. Causal and control beliefs (pp. 35-37). Windsor: NFER-NELSON.

Seth, P., Raiji, P., DiClemente, R., Wingood, G., \& Rose, E. (2009). Psychological distress as a correlate of a biologically confirmed STI, risky sexual practices, self-efficacy and communication with male sex partners in African-American female adolescents. Psychology Health and Medicine, 14, 291-300.

Sherbourne, C., \& Stewart, A. (1991). The MOS social support survey. Social Science and Medicine, 16, 493-527.

Sherr, L., Cluver, L., Toska, E., \& He, E. (2018). Differing psychological vulnerabilities among behaviourally and perinatally HIV infected adolescents in South Africa implications for targeted health service provision. AIDS Care, 30, 92-101.

Snider, L., \& Dawes, A. (2006). Psychosocial vulnerability and resilience measures for national-level monitoring of orphans and other vulnerable children: Recommendationsfor revision of the UNICEF psychological indicator. Cape Town: UNICEF.

Stangl, A. L., Lloyd, J. K., Brady, L. M., Holland, C. E., \& Baral, S. (2013). A systematic review of interventions to reduce HIV-related stigma and discrimination from 2002 to 2013: How far have we come? Journal of the International AIDS Society, 16(3 Suppl. 2), 18734 .

UNICEF. (2018). Turning the tide against AIDS will require more concentrated focus on adolescents and young people. Retrieved from https://data.unicef.org/topic/hivaids/ adolescents-young-people/\#

Vreeman, R., \& Carroll, A. (2007). A systematic review of school-based interventions to prevent bullying. Archives of Pediatric and Adolescent Medicine, 161, 78-88.

Vreeman, R., Scanlon, M., Marete, I., Mwangi, A., Inui, T., McAteer, C., \& Nyandiko, W. (2015). Characteristics of HIV-infected adolescents enrolled in a disclosure intervention trial in western Kenya. AIDS Care, 27, 6-17.

Ward, C., Artz, L., Leoschut, L., Kassanjee, R., \& Burton, P. (2018). Sexual violence against children in South Africa: A nationally representative cross-sectional study of prevalence and correlates. The Lancet Global Health, 6, e460-e468. 
Wong, V., Murray, K., Phelps, B., Vermund, S., \& McCarraher, D. (2017). Adolescents, young people, and the 90-90-90 goals: A call to improve HIV testing and linkage to treatment. Aids (London, England), 31, S191-S194.

Woollett, N., Black, V., Cluver, L. D., \& Brahmbhatt, H. (2017). Reticence in disclosure of HIV infection and reasons for bereavement: Impact on perinatally infected adolescents' mental health and understanding of HIV treatment and prevention in Johannesburg, South Africa. African Journal of AIDS Research, 16, 175-184.

Woollett, N., Cluver, L. D., Bandeira, M., \& Brahmbhatt, H. (2017). Identifying risks for mental health problems in HIV positive adolescents accessing HIV treatment in Johannesburg. Journal of Child and Adolescent Mental Health, 29, 11-26.

World Health Organization. (2011). Guideline on HIV disclosure counselling for children up to 12 years of age. Geneva: WHO Press.

Wouters, E., Van Dammeb, W., Van Loona, F., van Rensburg, D., \& Meulemansa, H. (2009). Public-sector ART in the free state province, South Africa: Community support as an important determinant of outcome. Social Science and Medicine, $69,1177-1185$. 